Int. J. Electrochem. Sci., 13 (2018) 9981 - 9998

International Journal of

ELECTROCHEMICAL

SCIENCE

www.electrochemsci.org

\title{
Investigation of Corrosion Inhibition of Welan Gum and Neem Gum on Reinforcing Steel Embedded in Concrete
}

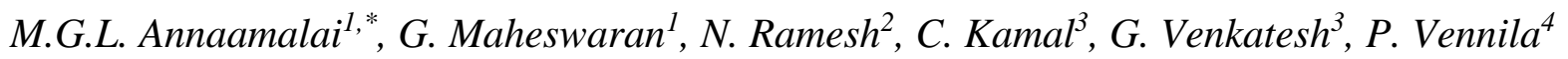 \\ ${ }^{1}$ Department of Civil Engineering, VSA Group of Institutions, Salem, Tamil Nadu, India. \\ ${ }^{2}$ Department of Civil Engineering, KS Rangasamy College of Technology, Namakkal, Tamil Nadu, \\ India. \\ ${ }^{3}$ Department of Chemistry, VSA Group of Institutions, Salem, Tamil Nadu, India. \\ ${ }^{4}$ Department of Chemistry, Thiruvalluvar Government Arts College, Rasipuram, Tamil Nadu, India. \\ *E-mail: annaamalaimgl@ gmail.com
}

doi: $10.20964 / 2018.10 .41$

Received: 13 May 2018 / Accepted: 27 June 2018 / Published: 1 September 2018

Two naturally derived gums namely Welan gum (WG) and Neem gum (NG) have been tested for their anti-corrosion potential against the steel reinforced in concrete in $\mathrm{NaCl}$ media at different time interval using standard corrosion characteristic techniques such as electrochemical impedance spectroscopy (EIS), Tafel polarization study (PDS) and scanning electron microscopy (SEM). The results of EIS and PDS revealed the protective film forming potential and mixed type inhibitive action of both the two gums. In addition, the formation of protective layer over embedded steel surface has been suggested by SEM. The density functional theory (DFT) results indicated the active centers of inhibitor molecules which could be attached on embedded steel surface that influence the anti-corrosion ability of WG and NG. The durability properties viz., compressive strength and split tensile strength were also improved on the introduction of gums to the concrete. The mechanism of inhibition of corrosion of steel embedded in concrete in $3.5 \% \mathrm{NaCl}$ solution by both the two gums has also been established.

Keywords: Welan gum, Neem gum, Electrochemical impedance spectroscopy, Tafel Polarization, Density Functional Theory, Reinforced steel.

\section{$\underline{\text { FULL TEXT }}$}

(C) 2018 The Authors. Published by ESG (www.electrochemsci.org). This article is an open access article distributed under the terms and conditions of the Creative Commons Attribution license (http://creativecommons.org/licenses/by/4.0/). 